\title{
Frequency of the Types of Alopecia at Twenty-Two Specialist Hair Clinics: A Multicenter Study
}

\author{
Sergio Vañó-Galván ${ }^{a}$ David Saceda-Corralo ${ }^{a} \quad$ Ulrike Blume-Peytavi ${ }^{b} \quad$ Jose Cucchía ${ }^{c}$ \\ Ncoza C. Dlova ${ }^{d}$ Maria Fernanda Reis Gavazzoni Dias ${ }^{e}$ Ramon Grimalt ${ }^{f}$ Daniela Guzmán-Sánchez ${ }^{g}$ \\ Matthew Harries ${ }^{\text {h }}$ Anthony Ho ${ }^{i}$ Susan Holmes ${ }^{j}$ Jorge Larrondok Anisa Mosam ${ }^{d}$ \\ Rui Oliveira-Soares ${ }^{1, m}$ Giselle M. Pinto ${ }^{n}$ Bianca M. Piraccini ${ }^{\circ}$ Rodrigo Pirmez $^{\mathrm{p}}$ \\ Daniel De la Rosa Carrillo ${ }^{q}$ Lidia Rudnicka ${ }^{r}$ Jerry Shapiro ${ }^{i}$ Rodney Sinclair ${ }^{\text {s, }}$ Antonella Tosti $^{\mathrm{u}}$ \\ Ralph M. Trüebv Annika Vogt ${ }^{\mathrm{b}}$ Mariya Mitevaw
}

\begin{abstract}
a Dermatology Department, Ramon y Cajal Hospital, University of Alcala, IRYCIS, Trichology Unit, Grupo Pedro Jaen Clinic, Madrid, Spain; ${ }^{b}$ Department of Dermatology and Allergy, Charité-Universitätsmedizin Berlin, Berlin, Germany; ${ }^{C}$ Private Trichology Practice, Santa Ana Medical Center, Bogotá, Colombia; ${ }^{\mathrm{d} D e p a r t m e n t ~ o f ~ D e r m a t o l o g y, ~ N e l s o n ~ R ~ M a n d e l a ~ S c h o o l ~}$

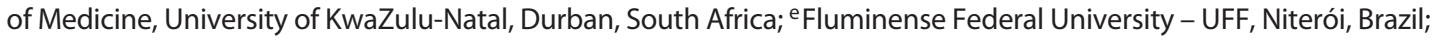
fDermatology Department, Universitat Internacional de Catalunya, Barcelona, Spain; ${ }^{9}$ School of Medicine, Universidad de Guadalajara, Guadalajara, Mexico; ${ }^{\mathrm{h}}$ The Dermatology Centre, University of Manchester, Salford Royal NHS Foundation Trust, Salford, UK; 'The Ronald O. Perelman Department of Dermatology, New York University School of Medicine, New York, NY,

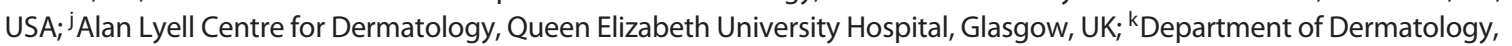
Clínica Alemana de Santiago, Facultad de Medicina Clínica Alemana, Universidad del Desarrollo, Santiago, Chile; 'Department of Dermatology, Hospital Cuf Descobertas, Lisbon, Portugal; 'mDepartment of Dermatology, Hospital Cuf Torres Vedras, Torres Vedras, Portugal; ${ }^{n}$ Hair and Scalp Diseases, Outpatient Clinic, Division of Dermatology, Santa Casa de Misericórdia, Porto Alegre, Brazil; ${ }^{\circ}$ Division of Dermatology, Department of Experimental, Diagnostic and Specialty Medicine, University

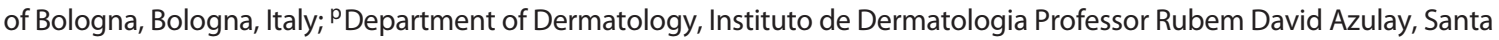
Casa da Misericórdia do Rio de Janeiro, Rio de Janeiro, Brazil; ${ }^{\circ D e p a r t m e n t ~ o f ~ D e r m a t o l o g y, ~ O s l o ~ U n i v e r s i t y ~ H o s p i t a l, ~ O s l o, ~}$ Norway; ' 'Department of Dermatology, Medical University of Warsaw, Warsaw, Poland; 's Sinclair Dermatology, East Melbourne,

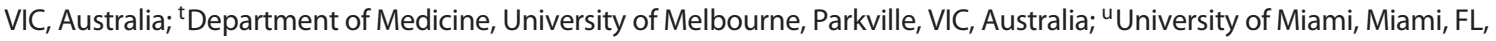
USA; ${ }^{\vee}$ Center for Dermatology and Hair Diseases Professor Trüeb, Wallisellen, Switzerland; ${ }^{w}$ Department of Dermatology and Cutaneous Surgery, University of Miami L. Miller School of Medicine, Miami, FL, USA
\end{abstract}

\section{Keywords \\ Hair diseases - Alopecia - Androgenetic alopecia - Alopecia areata - Frontal fibrosing alopecia - Telogen effluvium . Folliculitis decalvans · Lichen planopilaris · Epidemiology}

\section{Abstract \\ Background: The frequency of different types of alopecia is not clearly reported in recent studies. Objective: To analyze the frequency of the types of alopecia in patients consulting at specialist hair clinics (SHC) and to assess for global varia-}

tions. Methods: Multicenter retrospective study including data from patients evaluated at referral SHC in Europe, America, Africa and Australia. Results: A total of 2,835 patients (72.7\% females and $27.3 \%$ males) with 3,133 diagnoses of alopecia were included (73\% were non-cicatricial and $27 \%$ were cicatricial alopecias). In all, 57 different types of alopecia were characterized. The most frequent type was androgenetic alopecia (AGA) (37.7\%), followed by alopecia areata (AA) (18.2\%), telogen effluvium (TE) (11.3\%), frontal fibrosing alopecia (FFA) (10.8\%), lichen planopilaris (LPP) (7.6\%), folliculitis decalvans (FD) (2.8\%), discoid lupus (1.9\%)

\section{KARGER}

(C) 2019 S. Karger AG, Basel

E-Mail karger@karger.com

www.karger.com/sad
Sergio Vañó-Galván, MD, PhD

Dermatology Department, Ramon y Cajal Hospital

Carretera Colmenar Viejo km 9.100

ES-28034 Madrid (Spain)

E-Mail drsergiovano@gmail.com 
and fibrosing alopecia in a pattern distribution (FAPD) (1.8\%). There was a male predominance in patients with acne keloidalis nuchae, dissecting cellulitis and FD, and female predominance in traction alopecia, central centrifugal cicatricial alopecia, FFA, TE, FAPD and LPP. Conclusion: AGA followed by $A A$ and $T E$ were the most frequent cause of non-cicatricial alopecia, while FFA was the most frequent cause of cicatricial alopecia in all studied geographical areas.

(c) 2019 S. Karger AG, Basel

\section{Introduction}

Androgenetic alopecia (AGA) is the most frequent cause of hair loss in both genders [1-3], followed by alopecia areata (AA) [4]. Regarding cicatricial alopecias, lichen planopilaris (LPP) has been described as the most frequent cicatricial alopecia $[5,6]$. However, most papers published over recent years suggest that the incidence of frontal fibrosing alopecia (FFA) may be increasing compared with other types of cicatricial alopecias [7-9], although this observation has not yet been confirmed in large epidemiological studies. Some alopecias may have a marked difference in their prevalence depending on the geographical location and ethnicity (i.e., central centrifugal cicatricial alopecia [CCCA] is typical of females with African ancestry [7]); thus, a worldwide analysis of the frequency of the different alopecias seen at specialist hair clinics (SHC) may provide useful insights into disease epidemiology. Regarding the healthcare setting, no data exist regarding possible disparities in the frequency of hair disorders seen in private versus public centers.

There are no recent studies describing the frequency of different types of alopecia among patients treated at different SHC. The objective of this study was to analyze the frequency of the different types of alopecia in patients evaluated at SHC across the globe and to analyze the possible differences in frequencies between geographical areas, gender and age.

\section{Methods}

A multicenter retrospective study was designed, and local institutional review board approval was obtained. Data were collected at SHC in several countries between September 1st, 2017, and November 30th, 2017. The referral centers were located in Australia, Brazil, Chile, Colombia, Germany, Italy, Mexico, Norway, Poland, Portugal, South Africa, Spain, Switzerland, USA and UK. Each investigator included the following data: gender, age, setting (private vs. public healthcare), first visit versus follow-up visit and type of alopecia: AGA, telogen effluvium (TE), AA, FFA, LPP, discoid lupus, folliculitis decalvans (FD), CCCA, traction alopecia, dissecting cellulitis (DCS), acne keloidalis nuchae (AKN), fibrosing alopecia in a pattern distribution (FAPD), trichotillomania and others including hair shaft disorders and hair weathering changes. AA was subclassified into: patchy AA, ophiasis, diffuse AA, AA incognita, alopecia totalis, alopecia universalis and beard AA. Each investigator included data on a minimum of 100 consecutive patients consulting for any hair disorder in the study period. If a patient presented 2 or more concomitant alopecias, all were registered in the database.

The obtained data were anonymized and handled in accordance with the European General Data Protection Regulation (EU 2016/679).

For all continuous variables, median and range were calculated, but for categorical variables, frequencies were reported. The Mann-Whitney and $\chi^{2}$ tests were used to assess the statistical significance of differences observed between groups for continuous and categorical variables, respectively. $p<0.05$ was considered statistically significant. For all statistical analyses, a software package was used (SPSS 21.0; IBM Corp., Armonk, NY, USA).

\section{Results}

Results are summarized in Tables 1-3.

\section{Demographic Data}

In total, 2,835 patients were included (USA: $n=303$, Spain: $n=412$, Mexico: $n=100$, Chile: $n=137$, Colombia: $n=295$, Norway: $n=100$, Brazil: $n=312$, Portugal: $n=$ 100, Italy: $n=200$, Germany: $n=100$, Switzerland: $n=$ 100, South Africa: $n=114$, Australia: $n=107$, UK: $n=202$ and Poland: $n=253) .298$ patients $(10.5 \%)$ presented with two concomitant types of alopecia. A total of 3,133 alopecia diagnoses with 57 different types of alopecia were recorded and showed the following distribution: 2,293 were non-cicatricial alopecias (73.2\%) while 840 were cicatricial alopecias $(26.8 \%)$. The median age of patients was 43.5 years (range 1-92 years), and 2,062 patients were females (72.7\%) and 773 were males (27.3\%). 915 (32.3\%) were evaluated as a first visit and $1,920(67.7 \%)$ as a follow-up visit, and $1,925(67.9 \%)$ were seen in a private healthcare setting, while 910 (32.1\%) were seen in a public healthcare setting.

\section{Frequency in Alopecia by Type and Healthcare Setting}

The most frequent type of alopecia was AGA (37.7\%), followed by AA (18.2\%), TE (11.3\%) and FFA (10.8\%). There were statistically significant differences in the frequency of hair disorders depending on the healthcare setting (Table 1). In the private healthcare setting, the most frequent alopecia was AGA ( $48 \%$ of cases), followed by 
Table 1. Frequency of hair disorders and differences by setting (private/public healthcare)

\begin{tabular}{lccc}
\hline Type of alopecia & Public setting, $n(\%)$ & Private setting, $n(\%)$ & Total, $n(\%)$ \\
\hline Androgenetic alopecia & $136(14)$ & $1,044(48)$ & $1,180(37.7)$ \\
Alopecia areata & $274(28)$ & $294(13.6)$ & $568(18.2)$ \\
Telogen effluvium & $38(4)$ & $317(14.6)$ & $355(11.3)$ \\
Frontal fibrosing alopecia & $152(16)$ & $185(8.5)$ & $337(10.8)$ \\
Lichen planopilaris & $118(12)$ & $121(5.5)$ & $239(7.6)$ \\
Folliculitis decalvans & $61(6.3)$ & $27(1)$ & $88(2.8)$ \\
Discoid lupus & $42(4.3)$ & $18(<1)$ & $60(1.9)$ \\
FAPD & $42(4.3)$ & $15(<1)$ & $57(1.8)$ \\
Traction alopecia & $10(1.0)$ & $34(1.6)$ & $44(1.4)$ \\
CCCA & $9(1)$ & $21(1)$ & $30(1)$ \\
Dissecting cellulitis & $12(1)$ & $17(<1)$ & $29(0.9)$ \\
Acne keloidalis nuchae & $13(1.4)$ & $7(<1)$ & $17(0.5)$ \\
Trichotillomania & $5(<1)$ & $11(<1)$ & $12(0.4)$ \\
Hair shaft disorders & $1(<1)$ & $48(2.2)$ & $12(0.4)$ \\
Other alopecias & $47(4.9)$ & $2,171(69.3)$ & $95(3)$ \\
\hline Total & $962(30.7)$ & & $3,133(100)$ \\
\hline
\end{tabular}

TE (14.6\%), AA (13.6\%) and FFA (8.5\%). In the public healthcare setting, the most frequent alopecia was AA ( $28 \%$ of cases), followed by FFA (16\%), AGA (14\%) and LPP $(12 \%)(p=0.003)$.

\section{Frequency of Alopecia by Gender and Age}

Regarding gender (Table 2), the most frequent alopecias in male patients were: AGA (48\% of males), followed by AA (25\%), FD (6.9\%), LPP (5\%), TE (3.8\%), DCS (2.7\%), FFA (1.9\%), AKN (1.8\%), discoid lupus $(0.9 \%)$ and FAPD $(0.7 \%)$. The most frequent alopecias in female patients were: AGA (34.2\%), AA (15.7\%), FFA (14\%), TE (13.5\%), LPP (8.5\%), discoid lupus (2.3\%), FAPD $(2.2 \%)$, traction alopecia (1.9\%), FD (1.4\%) and CCCA (1.3\%).

The following alopecias were most frequent in male patients: AKN ( $88 \%$ were males), DCS (76\% were males), FD (64\% were males). A female predominance was observed in: traction alopecia (98\% were females), CCCA ( $97 \%$ were females), FFA (95\% were females), chronic and acute TE (93 and 90\% were females, respectively), FAPD ( $89 \%$ were females), discoid lupus ( $88 \%$ were females) and LPP (83\% were females).

Globally, male patients were younger than female patients (median age of 33 and 47 years, respectively; $p<$ 0.001 ). Analyzing the different alopecias by the age of patients (Table 2), the youngest median age was observed in patients with hair shaft disorders (14 years), followed by patients with trichotillomania (25 years), AKN (32 years),
AA (32 years), DCS (37 years), FD (40 years) and AGA (40 years). The oldest median age was observed in patients with FFA ( 60 years), FAPD ( 59 years), discoid lupus (56 years) and LPP (54 years).

\section{Non-Cicatricial Alopecia}

The most frequent type of non-cicatricial alopecia was AGA (51.5\% of non-cicatricial alopecias), followed by AA (24.9\%) and TE (15.5\%). Other types of alopecia such as trichotillomania, hair shaft disorders, hair weathering, syphilitic alopecia, scalp psoriasis, tinea capitis or anagen effluvium were present in less than $3 \%$ of patients. The most frequent hair shaft disorder was monilethrix ( 6 out of 12 patients), followed by trichorrhexis nodosa ( 3 out of 12 patients). Of the total of patients with AA $(n=568)$, the most frequent subtype was patchy AA (62.1\% of patients diagnosed with AA), followed by alopecia totalis (16.6\%), alopecia universalis $(9.5 \%)$, ophiasis $(5.8 \%)$, diffuse AA (4.1\%), AA incognita (1.4\%) and beard AA (0.5\%).

\section{Cicatricial Alopecia}

Regarding cicatricial alopecias ( $n=840,26.8 \%$ of the total of alopecias), FFA was the most frequent $(40.1 \%$ of cicatricial alopecias), followed by LPP (28.4\%), FD (10.5\%), discoid lupus (7.1\%), FAPD (6.8\%), traction alopecia $(5.2 \%)$, CCCA (3.6\%) and DCS $(3.4 \%)$.

Other types of alopecia such as AKN, erosive pustular dermatosis of the scalp, lamellar ichthyosis, permanent post-chemotherapy alopecia, temporal triangular con- 
Table 2. Differences in the frequency of hair disorders by gender and age

\begin{tabular}{|c|c|c|c|}
\hline \multirow[t]{2}{*}{ Type of alopecia } & \multirow[t]{2}{*}{ Gender } & \multicolumn{2}{|c|}{ Median age (range), years } \\
\hline & & by gender & total \\
\hline Androgenetic alopecia $(n=1,180)$ & $\begin{array}{l}\text { male: } 33 \% \\
\text { female: } 67 \%\end{array}$ & $\begin{array}{l}\text { male: } 33(11-76) \\
\text { female: } 45(12-91)\end{array}$ & $40(11-91)$ \\
\hline Alopecia areata $(n=568)$ & $\begin{array}{l}\text { male: } 36 \% \\
\text { female: } 64 \%\end{array}$ & $\begin{array}{l}\text { male: } 28(1-63) \\
\text { female: } 37(3-82)\end{array}$ & $32(1-82)$ \\
\hline Acute telogen effluvium $(n=183)$ & $\begin{array}{l}\text { male: } 10 \% \\
\text { female: } 90 \%\end{array}$ & $\begin{array}{l}\text { male: } 35(18-65) \\
\text { female: } 41(9-76)\end{array}$ & $41(9-76)$ \\
\hline Chronic telogen effluvium $(n=172)$ & $\begin{array}{l}\text { male: } 7 \% \\
\text { female: } 93 \%\end{array}$ & $\begin{array}{l}\text { male: } 31(17-86) \\
\text { female: } 43(13-92)\end{array}$ & $42(13-92)$ \\
\hline Frontal fibrosing alopecia $(n=337)$ & $\begin{array}{l}\text { male: } 5 \% \\
\text { female: } 95 \%\end{array}$ & $\begin{array}{l}\text { male: } 45(31-70) \\
\text { female: } 61(31-89)\end{array}$ & $60(31-89)$ \\
\hline Lichen planopilaris $(n=239)$ & $\begin{array}{l}\text { male: } 17 \% \\
\text { female: } 83 \%\end{array}$ & $\begin{array}{l}\text { male: } 43(13-74) \\
\text { female: } 56(8-86)\end{array}$ & $54(8-86)$ \\
\hline Folliculitis decalvans $(n=88)$ & $\begin{array}{l}\text { male: } 64 \% \\
\text { female: } 36 \%\end{array}$ & $\begin{array}{l}\text { male: } 40(19-73) \\
\text { female: } 41(17-75)\end{array}$ & $40(17-75)$ \\
\hline Discoid lupus $(n=60)$ & $\begin{array}{l}\text { male: } 12 \% \\
\text { female: } 88 \%\end{array}$ & $\begin{array}{l}\text { male: } 39(27-58) \\
\text { female: } 59(19-81)\end{array}$ & $56(19-81)$ \\
\hline FAPD $(n=57)$ & $\begin{array}{l}\text { male: } 11 \% \\
\text { female: } 89 \%\end{array}$ & $\begin{array}{l}\text { male: } 57(24-73) \\
\text { female: } 59(21-82)\end{array}$ & $59(21-82)$ \\
\hline Traction alopecia $(n=44)$ & $\begin{array}{l}\text { male: } 2 \% \\
\text { female: } 98 \%\end{array}$ & $\begin{array}{l}\text { male: } 44 \text { ( } 1 \text { case }) \\
\text { female: } 40(11-67)\end{array}$ & $41(11-67)$ \\
\hline $\operatorname{CCCA}(n=30)$ & $\begin{array}{l}\text { male: } 3 \% \\
\text { female: } 97 \%\end{array}$ & $\begin{array}{l}\text { male: } 56 \text { ( } 1 \text { case }) \\
\text { female: } 46(27-72)\end{array}$ & $47(27-72)$ \\
\hline Dissecting cellulitis $(n=29)$ & $\begin{array}{l}\text { male: } 76 \% \\
\text { female: } 24 \%\end{array}$ & $\begin{array}{l}\text { male: } 33(19-69) \\
\text { female: } 57(18-83)\end{array}$ & $37(18-83)$ \\
\hline Acne keloidalis nuchae $(n=17)$ & $\begin{array}{l}\text { male: } 88 \% \\
\text { female: } 12 \%\end{array}$ & $\begin{array}{l}\text { male: } 32(22-55) \\
\text { female: } 51(40-62)\end{array}$ & $32(22-62)$ \\
\hline Trichotillomania $(n=12)$ & $\begin{array}{l}\text { male: } 42 \% \\
\text { female: } 58 \%\end{array}$ & $\begin{array}{l}\text { male: } 25(14-41) \\
\text { female: } 25(8-35)\end{array}$ & $25(8-41)$ \\
\hline Hair shaft disorders $(n=12)$ & $\begin{array}{l}\text { male: } 42 \% \\
\text { female: } 58 \%\end{array}$ & $\begin{array}{l}\text { male: } 15(8-70) \\
\text { female: } 4(3-61)\end{array}$ & $14(3-70)$ \\
\hline Total $(n=3,133)$ & $\begin{array}{l}\text { male: } 26.4 \% \\
\text { female: } 73.6 \%\end{array}$ & $\begin{array}{l}\text { male: } 33(1-86) \\
\text { female: } 47(2-92)\end{array}$ & $43(1-92)$ \\
\hline
\end{tabular}

genital alopecia, pemphigus-induced alopecia, GrahamLittle syndrome, alopecia mucinosa or coupe de sabre alopecia were present in less than $3 \%$ of patients.

\section{Global Variations}

The different frequency of alopecias in each continent (Europe, America, Africa and Australia) was also analyzed (Table 3 ). We could not find any statistically sig- nificant difference in the frequency of AGA, TE, FFA and LPP. However, a higher frequency of some alopecias was found in some continents: AA in Europe ( 23 vs. $<14 \%$ in the rest of continents), traction alopecia in Africa (18 vs. $<1 \%$ in the rest of continents), AKN in Africa (9 vs. $<1 \%$ in the rest of continents), CCCA in Africa ( 6 vs. $<1 \%$ in the rest of continents), FD in Africa (7.5 vs. $<3.5 \%$ in the rest of continents) and FAPD in America (3.5 vs. $<2 \%$ in 
Table 3. Differences in the frequency of hair disorders by continent

\begin{tabular}{|c|c|c|c|c|c|}
\hline Type of alopecia & Europe, $n(\%)$ & America, $n(\%)$ & Australia, $n(\%)$ & Africa, $n(\%)$ & Total, $n(\%)$ \\
\hline Androgenetic alopecia & $558(35)$ & $531(41.2)$ & $85(69)$ & $6(4.5)$ & $1,180(37.6)$ \\
\hline Alopecia areata & $365(22.9)$ & $172(13.3)$ & $17(14)$ & $14(10.5)$ & $568(18.2)$ \\
\hline Telogen effluvium & $175(11)$ & $175(13.6)$ & 0 & $5(3.7)$ & $355(11.3)$ \\
\hline Frontal fibrosing alopecia & $177(11)$ & $134(10.4)$ & $9(7.3)$ & $17(12.7)$ & $337(10.8)$ \\
\hline Lichen planopilaris & $115(7.2)$ & $93(7.2)$ & $3(2.4)$ & $28(21)$ & $239(7.6)$ \\
\hline FAPD & $11(<1)$ & $45(3.5)$ & 0 & $1(1)$ & $57(1.8)$ \\
\hline Traction alopecia & $9(<1)$ & $10(<1)$ & $1(<1)$ & $24(18)$ & $44(1.4)$ \\
\hline CCCA & $7(<1)$ & $15(1)$ & 0 & $8(6)$ & $30(1)$ \\
\hline Dissecting cellulitis & $16(1)$ & $13(1)$ & 0 & 0 & $29(0.9)$ \\
\hline Acne keloidalis nuchae & $3(<1)$ & $2(<1)$ & 0 & $12(9)$ & $17(0.5)$ \\
\hline Trichotillomania & $6(<1)$ & $5(<1)$ & 0 & $1(1)$ & $12(0.4)$ \\
\hline
\end{tabular}

the rest of continents). Analyzing each continent by countries, there were no significant differences in the frequency of hair disorders. In the American continent, we performed a subanalysis between North America $(n=$ $352)$ and South America $(n=934)$. We found a statistically significant higher number of patients consulting for these alopecias in North America: FFA (16\% of patients in North America vs. 8.4\% of patients in South America, $p<0.001$ ), CCCA ( 2.8 vs. $0.5 \%, p=0.002$ ). On the contrary, more patients consulted for these alopecias in South America: FAPD (4.7\% of patients in South America vs. $0.3 \%$ of patients in North America, $p<0.001$ ), discoid lupus ( 4.3 vs. $0.3 \%, p<0.001)$ and $\mathrm{FD}(2$ vs. $0.3 \%, p=0.014)$. We did not find any statistically significant difference in the age of the different alopecias between continents.

\section{Discussion}

This is the first multicenter study to analyze the frequencies of the different types of alopecia in patients from reference SHC in different continents. An understanding of the frequency with which different types of alopecia are seen in different geographical areas could provide useful insights into disease epidemiology.

In concordance with previous studies [1-3, 10], AGA was the most frequent cause of consultation in both genders. Male patients that consulted with AGA in our study were younger than female patients ( 33 vs. 45 years, re- spectively), similar to other studies [1]. This could be explained because female patients present two peaks of consultation for AGA: early adults and menopause, while male patients usually consult in the early adulthood.

The second most frequent global cause of consultation in our study was AA. This was the most frequent type of alopecia in the public healthcare setting. The median age in patients with AA was 32 years, in accordance with published studies (30-35 years) $[4,11,12]$. AA seems to affect both genders equally [11], although in our study we found a female predominance (64\% females vs. $36 \%$ males), probably because female patients tend to consult more than male patients.

TE was the third most frequent cause of consultation, with a clear female predominance, in concordance with previous reports [13]. Other types of non-cicatricial alopecia such as trichotillomania, tinea capitis or scalp psoriasis were less frequent. Monilethrix represented the most frequent hair shaft disorder in our study.

Regarding gender, patients consulting with AKN, FD and DCS were most frequently males, while patients consulting with traction alopecia, CCCA, FFA, FAPD and LPP were most frequently females, in accordance with the literature $[7,9,14-20]$. The most frequent alopecias in both genders were AGA followed by AA. Remarkably, the third most frequent alopecia in male patients was FD, while in female patients was FFA, supporting the already reported gender predominance in both alopecias $[9,15]$. 
Regarding age, we also found similar results to previous reports $[6,9,14-18,21,22]$ (youngest patients in $\mathrm{AKN}, \mathrm{AA}, \mathrm{DCS}$ and FD, and oldest patients in FFA, FAPD, discoid lupus and LPP).

The group of cicatricial alopecias represented the $27 \%$ of patients consulting at SHC in our study, a significantly higher percentage than the $7 \%$ published by Whiting in 2001 [22] or the 3\% reported by Tan et al. in 2004 [21]. This difference may be explained by the increasing incidence and improved diagnostic of FFA in the recent years. In fact, FFA was the most frequent cause of cicatricial alopecias in all the analyzed areas in our study, supporting the apparent increasing incidence in the recent years $[9,10,23]$. This finding would also support the concept that environmental factors with worldwide distribution might play a role in the pathogenesis of FFA. Another interesting finding was the increasing number of patients diagnosed with FAPD (57 cases, $6.8 \%$ of cicatricial alopecias). This entity was described by Zinkernagel and Trüeb in 2000 [18] and has been rarely reported in other epidemiological studies [14, 21, 24, 25] being probably underdiagnosed. In our study, FAPD patients were predominantly females (89\%) with a median age of 59 years, which is in concordance with earlier reports (Zinkernagel and Trüeb [18]: 19 patients, 79\% females, median age 60 years; Mardones et al. [26]: 12 cases, 70\% females, median age 48 years). In our opinion, FAPD should be included in future classifications of cicatricial alopecias.

We analyzed the differences in the frequency of hair disorders depending on the healthcare setting private versus public. Interestingly, AA and FFA were the most frequent cause of consultation in SHC at public centers. Besides the potentially great impact on quality of life of these alopecias [27, 28], the symptomatic presentation (FFA) or the requirement in some patients with AA for complex therapies such as immunosuppressive drugs, contact immunotherapy or corticosteroid injections may explain the frequency of these alopecias at public centers.

When we compared the frequency of alopecias by continents, we found results concordant with the literature (traction alopecia, AKN, CCCA and FD more frequent in Africa) [7, 14]. Interestingly, we found a higher frequency of FFA in North America compared with South America, with an opposite result for FAPD, which was more frequent in South America. Another difference between continents was the higher frequency of AA in European patients compared to the rest of continents, a finding not previously described in the literature to our knowledge.
Our study has some limitations. Firstly, the subgroups of patients evaluated at SHC located in Australia and Africa were small. Secondly, we did not include patients evaluated in Asia. It should be noted that the presented data in our study do not reflect the incidence or prevalence of alopecias, either in the general population, or in the general practitioner setting, but the frequency of hair disorders in patients seeking expert specialist hair opinion or referred to tertiary centers. Thus, although the presented frequencies of alopecias should not be considered as synonymous with "incidence" or "prevalence," it does provide valuable information on the current frequency of hair disorders in patients consulting at specialist hair centers, which may be useful for clinicians and epidemiologists.

\section{Conclusions}

The most frequent type of alopecia evaluated at SHC was AGA, followed by AA, TE and FFA. Patients consulting with AKN, DCS and FD were predominantly males, while patients consulting with traction alopecia, CCCA, FFA, TE, FAPD and LPP were predominantly females. FFA was the most frequent cicatricial alopecia in all the studied geographical areas, followed by LPP and FD.

A total of 57 different diagnoses of alopecia were performed, showing the complexity of the diagnosis of hair disorders. It highlights the importance of medical and dermatologic evaluation in the management of patients with hair loss.

\section{Acknowledgements}

A donation from Novartis (NF 516/2016) to the Dermatology Department of Ramon y Cajal Hospital was used for financial support of statistical analysis and data management services.

We want to acknowledge Dr. Hudson Dutra for his help in the acquisition of data.

\section{Statement of Ethics}

The study protocol was reviewed and approved by Ramon y Cajal Ethical Committee.

\section{Disclosure Statement}

The authors declare no conflicts of interest. 


\section{References}

1 Salman KE, Altunay IK, Kucukunal NA, Cerman AA. Frequency, severity and related factors of androgenetic alopecia in dermatology outpatient clinic: hospital-based cross-sectional study in Turkey. An Bras Dermatol. 2017 Jan-Feb;92(1):35-40.

2 Gan DCC, Sinclair RD. Prevalence of male and female pattern hair loss in Maryborough. J Investig Dermatol Symp Proc. 2005 Dec; 10(3):184-9.

3 Kaliyadan F, Nambiar A, Vijayaraghavan S. Androgenetic alopecia: an update. Indian J Dermatol Venereol Leprol. 2013 Sep-Oct; 79(5):613-25.

4 Dainichi T, Kabashima K. Alopecia areata: what's new in epidemiology, pathogenesis, diagnosis, and therapeutic options? J Dermatol Sci. 2017 Apr;86(1):3-12.

5 Headington JT. Cicatricial alopecia. Dermatol Clin. 1996 Oct;14(4):773-82. Available from: http://www.ncbi.nlm.nih.gov/pubmed/ 9238335

6 Otberg N, Wu WY, McElwee KJ, Shapiro J. Diagnosis and management of primary cicatricial alopecia: part I. Skinmed. 2008 Jan-Feb; 7(1):19-26.

7 Bolduc C, Sperling LC, Shapiro J. Primary cicatricial alopecia: other lymphocytic primary cicatricial alopecias and neutrophilic and mixed primary cicatricial alopecias. J Am Acad Dermatol. 2016 Dec;75(6):1101-17.

8 Holmes S. Frontal Fibrosing Alopecia. Skin Therapy Lett. 2016 Jul;21(4):5-7. Available from: http://www.ncbi.nlm.nih.gov/pubmed/ 27388531

9 Vañó-Galván S, Molina-Ruiz AM, SerranoFalcón C, Arias-Santiago S, Rodrigues-Barata AR, Garnacho-Saucedo G, et al. Frontal fibrosing alopecia: a multicenter review of 355 patients. J Am Acad Dermatol. 2014 Apr; 70(4):670-8.

10 Pindado-Ortega C, Saceda-Corralo D, Buendía-Castaño D, Fernández-González P, Moreno-Arrones ÓM, Fonda-Pascual P, et al. Prescribing Habits for Androgenic Alopecia among Dermatologists in Spain in 2017: A Cross-Sectional Study. Actas Dermosifiliogr. 2018 Jul - Aug;109(6):536-42.
11 Strazzulla LC, Wang EH, Avila L, Lo Sicco K, Brinster N, Christiano AM, et al. Alopecia areata: disease characteristics, clinical evaluation, and new perspectives on pathogenesis. J Am Acad Dermatol. 2018 Jan;78(1):1-12.

12 Mirzoyev SA, Schrum AG, Davis MD, Torgerson RR. Lifetime incidence risk of alopecia areata estimated at $2.1 \%$ by Rochester Epidemiology Project, 1990-2009. J Invest Dermatol. 2014 Apr;134(4):1141-2.

13 García-Hernández MJ, Camacho FM. Chronic telogen effluvium: incidence, clinical and biochemical features, and treatment. Arch Dermatol. 1999 Sep;135(9):1123-4. Available from: http://www.ncbi.nlm.nih.gov/pubmed/ 10490125

14 Bolduc C, Sperling LC, Shapiro J. Primary cicatricial alopecia: lymphocytic primary cicatricial alopecias, including chronic cutaneous lupus erythematosus, lichen planopilaris, frontal fibrosing alopecia, and Graham-Little syndrome. J Am Acad Dermatol. 2016 Dec; 75(6):1081-99.

15 Vañó-Galván S, Molina-Ruiz AM, Fernández-Crehuet P, Rodrigues-Barata AR, AriasSantiago S, Serrano-Falcón C, et al. Folliculitis decalvans: a multicentre review of 82 patients. J Eur Acad Dermatol Venereol. 2015 Sep; 29(9):1750-7.

16 Soares VC, Mulinari-Brenner F, Souza TE. Lichen planopilaris epidemiology: a retrospective study of 80 cases. An Bras Dermatol. 2015 Sep-Oct;90(5):666-70.

17 Segurado-Miravalles G, Camacho-Martínez FM, Arias-Santiago S, Serrano-Falcón C, Serrano-Ortega S, Rodrigues-Barata R, et al. Epidemiology, clinical presentation and therapeutic approach in a multicentre series of dissecting cellulitis of the scalp. J Eur Acad Dermatol Venereol. 2017 Apr;31(4):e199200.

18 Zinkernagel MS, Trüeb RM. Fibrosing alopecia in a pattern distribution: patterned lichen planopilaris or androgenetic alopecia with a lichenoid tissue reaction pattern? Arch Dermatol. 2000 Feb;136(2):205-11.
19 Meinhard J, Stroux A, Lünnemann L, Vogt A Blume-Peytavi U. Lichen planopilaris: Epidemiology and prevalence of subtypes - a retrospective analysis in 104 patients. J Dtsch Dermatol Ges. 2014;12(3):229-235, 229-236.

$20 \mathrm{Na} \mathrm{K}, \mathrm{Oh} \mathrm{SH}$, Kim SK. Acne keloidalis nuchae in Asian: A single institutional experience. PLoS One. 2017;12(12):e0189790.

21 Tan E, Martinka M, Ball N, Shapiro J. Primary cicatricial alopecias: clinicopathology of 112 cases. J Am Acad Dermatol. 2004 Jan; 50(1):25-32.

22 Whiting DA. Cicatricial alopecia: clinicopathological findings and treatment. Clin Dermatol. 2001 Mar-Apr; 19(2):211-25. Available from: http://www.ncbi.nlm.nih. gov/pubmed/11397600

23 Lamb RC, Young D, Holmes S. Retrospective review of diphencyprone in the treatment of alopecia areata. Clin Exp Dermatol. 2016 Jun; 41(4):352-8

24 Griffin LL, Michaelides C, Griffiths CE, Paus R, Harries MJ. Primary cicatricial alopecias: a U.K. survey. Br J Dermatol. 2012 Sep;167(3): 694-7.

25 Katoulis AC, Diamanti K, Sgouros D, Liakou AI, Bozi E, Avgerinou G, et al. Is there a pathogenetic link between frontal fibrosing alopecia, androgenetic alopecia and fibrosing alopecia in a pattern distribution? J Eur Acad Dermatol Venereol. 2018 Jun;32(6):e218-20.

26 Mardones F, Hott K, Martinez MC. Clinical study of fibrosing alopecia in a pattern distribution in a Latin American population. Int J Dermatol. 2018 Feb;57(2):e12-4.

27 Saceda-Corralo D, Pindado-Ortega C, Moreno-Arrones ÓM, Fernández-González P, Rodrigues-Barata AR, Jaén-Olasolo $\mathrm{P}$, et al. Health-Related Quality of Life in Patients With Frontal Fibrosing Alopecia. JAMA Dermatol. 2018 Apr;154(4):479-80.

28 Jun M, Keum DI, Lee S, Kim BJ, Lee WS. Quality of Life with Alopecia Areata versus Androgenetic Alopecia Assessed Using Hair Specific Skindex-29. Ann Dermatol. 2018 Jun; 30(3):388-91. 